\title{
PENGARUH KOMPOSISI MASERAL BATUBARA MUARA WAHAU TERHADAP PERILAKU TERMAL MENGGUNAKAN PENDEKATAN PIROLISIS DENGAN THERMOGRAVIMETRIC ANALYSIS (TGA)
}

\author{
Agus Haris Widayat ${ }^{1)^{*}}$, Komang Anggayana1), Basuki Rahmad²) dan Luthfi Hafizh Azhar ${ }^{3)}$ \\ 1)Kelompok Keahlian Eksplorasi Sumberdaya Bumi, Fakultas Teknik Pertambangan dan Perminyakan, \\ Institut Teknologi Bandung \\ 2)Fakultas Teknologi Mineral, UPN "Veteran” Yogyakarta \\ 3)Program Studi Teknik Pertambangan, Fakultas Teknik Pertamanbangan dan Perminyakan, Institut \\ Teknologi Bandung
}

Artikel masuk : 26-03-2021, Artikel diterima : 31-03-2021

\begin{abstract}
Kata kunci:
batubara, maseral, inertinit,

thermogravimetric analysis

Keywords:

coal, maceral, inertinite, thermogravimetric analysis
\end{abstract}

\begin{abstract}
ABSTRAK
Empat conto batubara dari daerah Muara Wahau telah diteliti untuk mengetahui karakteristik termal dengan pendekatan analisis pirolisis dan perangkat thermogravimetric analysis (TGA). Perilaku termal ini dapat memberikan gambaran yang dialami oleh batubara selama proses pembatubaraan di alam, pembatubaraan buatan, salah satu proses yang terjadi pada gasifikasi batubara bawah tanah, pencairan batubara, dan lain-lain. Analisis proksimat, ultimat, dan petrografi batubara juga dilakukan untuk mengetahui komposisi bahan organik yang terkandung di dalamnya. Hasil analisis menunjukkan bahwa batubara Muara Wahau mempunyai komposisi maseral inertinit yang cukup bervariasi dari 6\% hingga 18\% (v/v). Analisis TGA menunjukkan bahwa semakin tinggi kandungan maseral inertinit, penurunan massa conto secara umum semakin rendah. Hal ini menunjukkan bahwa maseral inertinit cenderung tidak berevolusi selama proses pemanasan. Hasil ini memberikan implikasi bahwa batubara yang mengandung maseral inertinit kurang direkomendasikan untuk jenis pemanfaatan yang dipengaruhi oleh reaktivitas maseral seperti gasifikasi dan pencairan.
\end{abstract}

${ }^{*}$ Corresponding author: haris@mining.itb.ac.id

Doi : https://doi.org/10.36986/impj.v2i2.33 


\section{ABSTRACT}

Four coal samples from Muara Wahau has been studied to investigate the thermal characteristics by mean of thermogravimetric analysis (TGA). The thermal behavior is important to simulate the coal during coalification in nature, artificial coalification, and coal beneficiations including gasification and liquefaction. Proximate, ultimate and petrographical analyses were performed to identify the composition of the coal samples. Petrographical analysis revealed the coal samples contain varying inertinite maceral from $6 \%$ to $18 \%(\mathrm{~V} / \mathrm{V})$. Thermogravimetric analysis showed that the higher inertinite maceral content, the lesser coal reactivity. It imply that the maceral does not undergo significant evolution during heating. The coal with high inertinitte content might be, therefore, not suitable for utilization which require high coal reactivity such as gasification or liquefaction.

\section{PENDAHULUAN}

Batubara umumnya dimanfaatkan karena kandungan panasnya, baik dengan pembakaran konvensional secara langsung maupun jenis-jenis pemanfaatan non-konvensional melalui proses gasifikasi dan pencairan. Pemanfaatan batubara domestik paling besar saat ini adalah sebagai batubara termal yang dibakar secara konvensional, yaitu mencapai sekitar $71 \%$ untuk PLTU (99 juta ton) (Ditjen Minerba, 2020). Selain itu batubara juga dimanfaatkan di pabrik-pabrik semen, tekstil, baja, smelter, dan sebagainya dengan jumlah yang lebih sedikit. Pemanfaatan batubara secara non-konvensional seperti gasifikasi dan pencairan pada saat ini masih belum dilakukan dalam skala besar di industri.
Meskipun demikian, beberapa perusahaan dan lembaga sudah mulai merintis proyek gasifikasi termasuk underground coal gasification di beberapa lokasi di Indonesia.

Pemanfaatan batubara secara non-konvensional dapat menjadi salah satu opsi yang menarik untuk mendukung pasokan energi nasional. Hal ini disebabkan pemanfaatan batubara termal konvensional terus mendapatkan ancaman terutama terkait dengan isu lingkungan, sementara kebutuhan energi nasional terus meningkat dari tahun ke tahun. Masih sedikitnya pemanfaatan batubara nonkonvensional yang lebih ramah lingkungan dengan demikian memberikan tantangan dan peluang untuk mengembangkannya ke depan.

Pengembangan diversifikasi pemanfaatan batubara secara non-konvensional memerlukan studi yang lebih detil. Karakterisasi batubara yang diperlukan tidak sebatas pada kandungan kalori, komposisi proksimat, atau analisis umum yang lain, namun juga memerlukan pendekatan lanjut yang lebih komprehensif. Pada studi ini dilakukan investigasi pengaruh komposisi batubara terhadap perilaku termal selama proses pemanasan. Perilaku termal dapat memberikan masukan untuk menentukan jenis pemanfaatan batubara yang paling optimal. Komposisi batubara ditentukan dengan analisis proksimat, ultimat, dan petrografi untuk menentukan kandungan maseral. Perilaku termal diidentifikasi dengan menggunakan perangkat thermogravimetric analysis (TGA).

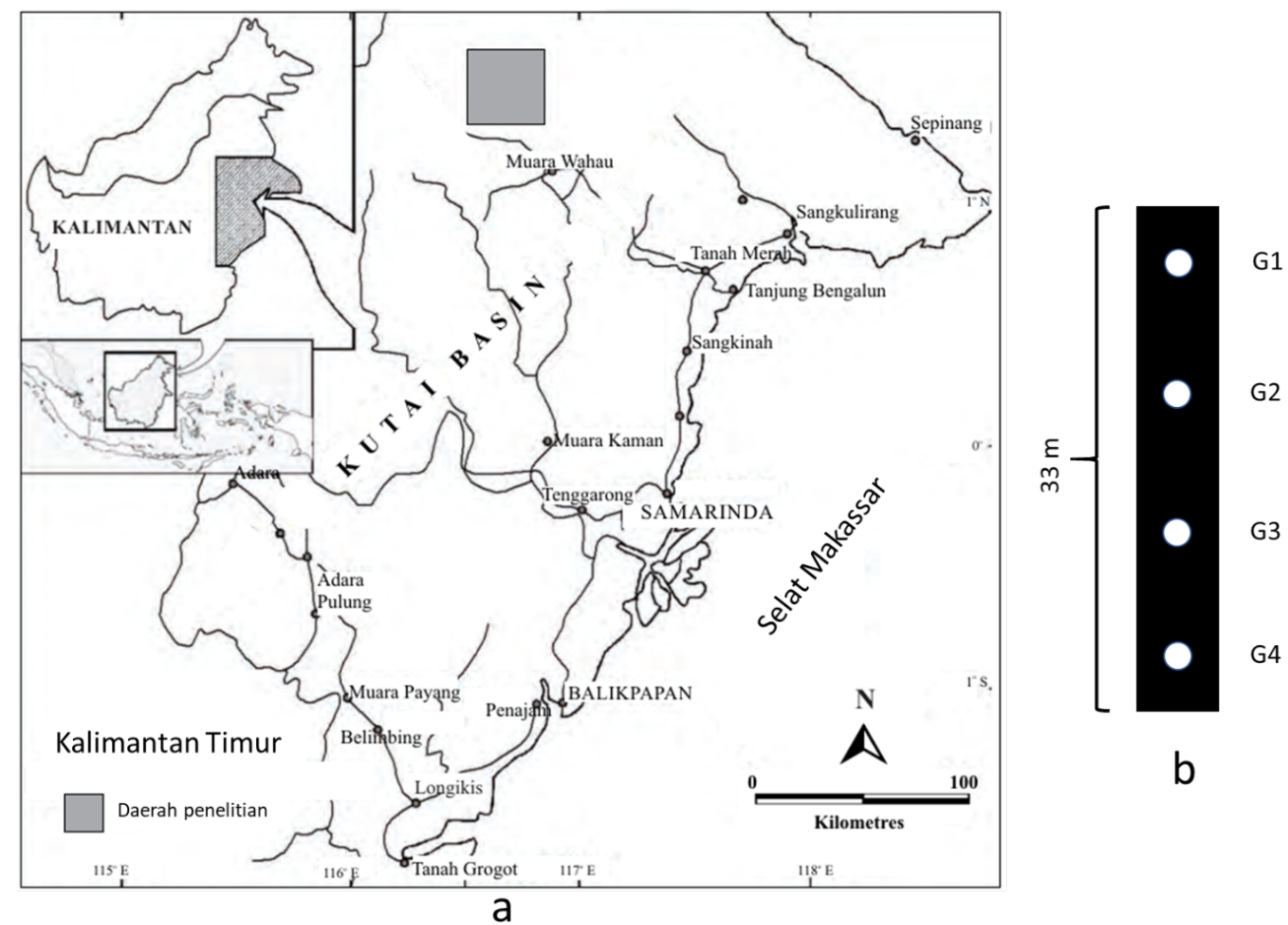

Gambar 1. Lokasi penelitian dan titik-titik sampel pada seam batubara. 


\section{KONDISI GEOLOGI}

Lokasi penelitian berada di Kecamatan Muara Wahau, Kabupaten Kutai Timur, Provinsi Kalimantan Timur (Gambar 1a). Kecamatan Muara Wahau termasuk dalam Cekungan Kutai yang merupakan cekungan penting di Indonesia terkait dengan potensi hidrokarbon.

Di daerah penelitian umumnya tersingkap Formasi Muarawahau yang berumur Miosen Awal (Supriatna dan Abidin, 1995). Formasi ini terdiri dari bagian atas dan bagian bawah. Bagian atas formasi tersusun atas batulempung, batupasir kuarsam sisipan tufa, dan batubara. Bagian bawah Formasi Muarawahau terdiri dari batugamping yang kaya fosil, ganggang, dan koral.

Batubara di daerah penelitian terdiri dari dua seam utama dengan ketebalan 15 hingga $62 \mathrm{~m}$ dan kemiringan lapisan bervariasi dari $8^{\circ}$ hingga $12^{\circ}$. Secara umum batubara di daerah ini berwarna hitam kecoklatan, keras, kusam, dan mengandung resin dan fosil kayu di beberapa bagian. Empat sampel batubara diambil dari inti bor salah satu seam utama (Seam 1) yang mempunyai ketebalan penembusan bor sekitar $33 \mathrm{~m}$. Gambar 1b menampilkan titik-titik dimana dilakukan pengambilan sampel pada Seam 1.

\section{METODOLOGI PENELITIAN}

Sampel batubara terlebih dahulu dipreparasi dengan peremukan dan dilanjutkan penggerusan. Butiran batubara kemudian diayak untuk memperoleh ukuran butir $<75$ mikrometer untuk analisis proksimat, ultimat, dan termogravimetri, dan ukuran butir $<1 \mathrm{~mm}$ untuk analisis maseral.

\section{Analisis Proksimat, Ultimat dan Kandungan Kalori}

Analisis proksimat merupakan analisis untuk mengetahui komposisi utama pembentuk batubara yang terdiri dari empat parameter yaitu kandungan air (moisture content), zat terbang (volatile matter), karbon tertambang (fixed carbon), dan kandungan abu (ash content). Analisis proksimat yang dilakukan mengikuti standar ASTM D3173, D3174, dan ISO 5071-1.

Analisis ultimat merupakan analisis untuk menentukan komposisi unsur kimia dalam batubara yang terdiri dari kandungan karbon (C), hidrogen $(\mathrm{H})$, oksigen $(\mathrm{O})$, sulfur $(\mathrm{S})$, dan nitrogen (N). Analisis ultimat dilakukan dengan mengikuti standar ASTM D3178, D3179, dan D4239. Analisis kandungan kalori mengikuti standar ASTM D2015. Analisis proksimat, ultimat, dan kandungan kalori dilaksanakan di Puslitbang Tekmira, Bandung.

\section{Analisis Maseral}

Analisis maseral mengikuti metode yang telah dideskripsikan oleh Taylor dkk. (1998). Partikel batubara yang berukuran $<1 \mathrm{~mm}$ dicetak dalam resin dan kemudian dipoles. Pengamatan maseral menggunakan mikroskop Zeiss Axio Imager A2m di Laboratorium Mineralogi, Mikroskopi, dan Geokimia, Institut Teknologi Bandung. Identifikasi maseral menggunakan nomenklatur menurut sistem ICCP 1994.

\section{Analisis Termogravimetri}

Thermogravimetric analysis (TGA) merupakan analisis untuk mengetahui kehilangan massa sampel selama proses pemanasan. Semakin cepat dan banyaknya kehilangan massa selama analisis mengindikasikan material sampel yang lebih reaktif (Bryers, 1995; Zhao dkk., 2011). Sekitar 25 mg sampel yang sudah halus dimasukkan ke perangkat TGA dengan medium nitrogen dan aliran gas $20 \mathrm{ml} /$ menit. Sampel dikondisikan terlebih dahulu pada temperatur $40^{\circ} \mathrm{C}$ selama 1 menit. Kemudian sampel dipanaskan dengan laju pemanasan $10^{\circ} \mathrm{C} /$ menit hingga mencapai temperatur $815^{\circ} \mathrm{C}$ dan dikondisikan secara isotermal selama 30 menit. Penurunan massa selama proses pemanasan dicatat secara otomatis oleh komputer untuk diolah dan diinterpretasikan lebih lanjut. Analisis TGA dilakukan di National Coal Institut, Oviedo, Spanyol.

\section{HASIL DAN PEMBAHASAN}

Analisis proksimat mengindikasikan kandungan air bervariasi dari 20\% hingga $27 \%$ (adb), kandungan zat terbang dari $51 \%$ sampai $58 \%(\mathrm{db})$, dan kandungan karbon tertambat sekitar 39\% hingga $46 \%$ (db). Kandungan abu dari keempat sampel batubara yang dianalisis menghasilkan nilai yang mirip yaitu sekitar 2,5\% sampai 2,8\% (db). Sampel G2 menunjukkan komposisi zat terbang yang lebih tinggi dan karbon tertambat yang lebih rendah dibandingkan dengan tiga sampel yang lainnya. Analisis ultimat menunjukkan kandungan unsur karbon, hidrogen, nitrogen, dan sulfur yang mirip pada keempat sampel. Sementara hasil analisis kandungan kalori menghasilkan nilai sekitar 4800$5000 \mathrm{kal} / \mathrm{kg}$ (adb). Hasil lengkap analisis proksimat, ultimat, dan kandungan kalori dapat dilihat pada Tabel 1. 
Tabel 1. Hasil analisis proksimat, ultimat, dan kandungan kalori batubara Muara Wahau.

\begin{tabular}{|c|c|c|c|c|c|c|c|c|c|}
\hline \multirow{3}{*}{$\begin{array}{c}\text { No } \\
\text { Sampel }\end{array}$} & \multicolumn{4}{|c|}{ Analisis Proksimat } & \multicolumn{4}{|c|}{ Analisis Ultimat } & \multirow{3}{*}{\begin{tabular}{|c|}
$\begin{array}{c}\text { Analisis } \\
\text { Kandungan Kalori }\end{array}$ \\
kal/gr, adb \\
\end{tabular}} \\
\hline & Moisture & Ash & VM & FC & C & $\mathbf{H}$ & $\mathbf{N}$ & $\mathbf{S}$ & \\
\hline & $\%, a d b$ & \multicolumn{3}{|c|}{$\%, \mathrm{db}$} & \multicolumn{4}{|c|}{$\%, \mathrm{db}$} & \\
\hline $\mathrm{G} 1$ & 22,72 & 2,47 & 51,17 & 46,36 & 67,21 & 4,52 & 1,01 & 0,12 & 4.800 \\
\hline $\mathrm{G} 2$ & 26,69 & 2,70 & 57,91 & 39,39 & 68,37 & 4,72 & 1,06 & 0,15 & 4.850 \\
\hline G3 & 20,39 & 2,49 & 51,27 & 46,24 & 68,60 & 4,92 & 0,91 & 0,12 & 5.015 \\
\hline G4 & 24,58 & 2,81 & 53,39 & 43,80 & 67,39 & 4,59 & 1,03 & 0,15 & 4.835 \\
\hline
\end{tabular}

Tabel 2. Hasil analisis maseral batubara Muara Wahau

\begin{tabular}{|c|c|c|c|c|c|}
\hline \multirow{2}{*}{$\begin{array}{c}\text { No } \\
\text { Sampel }\end{array}$} & Huminit & Liptinit & Inertinit & Mineral & \multirow{2}{*}{$\begin{array}{l}\mathrm{Rr} \\
\% \\
\end{array}$} \\
\hline & \multicolumn{4}{|c|}{$\%$ v/v } & \\
\hline G1 & 77,4 & 5,6 & 13,6 & 3,4 & 0,43 \\
\hline G2 & 87,8 & 1,8 & 6,4 & 4,0 & 0,43 \\
\hline G3 & 73,4 & 4,8 & 18,4 & 3,4 & 0,42 \\
\hline G4 & 82,6 & 3,2 & 7,6 & 6,6 & 0,42 \\
\hline
\end{tabular}

Analisis maseral menunjukkan kandungan huminit mendominasi antara $73 \%$ dan $88 \%(\mathrm{v} / \mathrm{v})$, sedangkan maseral liptinit umumnya di bawah $5 \%$ (v/v). Kandungan inertinit pada keempat sampel mengindikasikan adanya perbedaan yang ekstrem, yaitu antara 6\% dan 18\% (v/v). Sampel G1 dan G3 mempunyai kandungan inertinit yang jauh lebih melimpah dibandingkan dengan sampel G2 dan G4 (Tabel 2). Gambar 2 menampilkan fotomikrograf sampel G2 yang mempunyai kandungan inertinit terbatas dan sampel G3 yang mempunyai kandungan inertinit lebih melimpah. Pengukuran reflektansi vitrinit menghasilkan nilai relatif rendah yaitu sekitar $0,42 \%$ untuk keempat sampel tersebut. Hal ini menunjukkan peringkat batubara batubara Seam 1 tersebut adalah sub-bituminous $\mathrm{C}$ menurut klasifikasi Stach dkk. (1982).

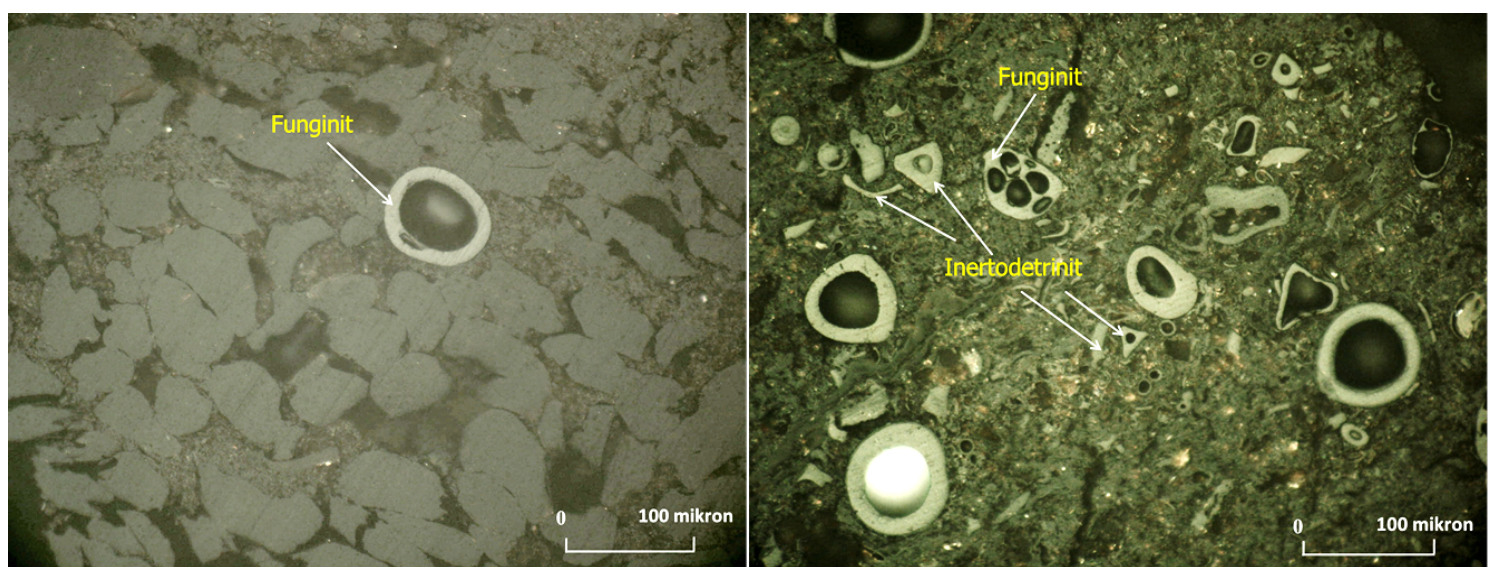

Gambar 2. Kiri: fotomikrograf sampel G2 yang relatif sedikit mengandung sedikit maseral inertinit, tampak funginit (inertinit) berada di antara korpogelinit (huminit). Kanan: fotomikrograf sampel G3 yang mengandung berlimpah maseral inertinit, tampak funginit dan inertodetrinit di antara humodetrinit.

Analisis TGA dilakukan pada dua sampel yang menunjukkan komposisi paling berbeda, yaitu sampel G2 dan G3. Kedua sampel tersebut mempunyai kandungan air, zat terbang, dan maseral inertinit yang signifikan. Hasil pengukuran dengan TGA menghasilkan termogram seperti yang ditunjukkan pada Gambar 3. Termogram ditampilkan sebagai penurunan massa selama proses pemanasan (TG) maupun sebagai turunannya atau laju penurunan massa (diferensial, DTG). Berdasarkan termogram tersebut, karakteristik termal batubara dapat dibagi menjadi 4 tahap, yaitu tahap $1\left(40-130^{\circ} \mathrm{C}\right)$, tahap $2\left(130-250^{\circ} \mathrm{C}\right)$, tahap 3 $\left(250-600^{\circ} \mathrm{C}\right)$, dan tahap $4\left(600-815^{\circ} \mathrm{C}\right)$. 

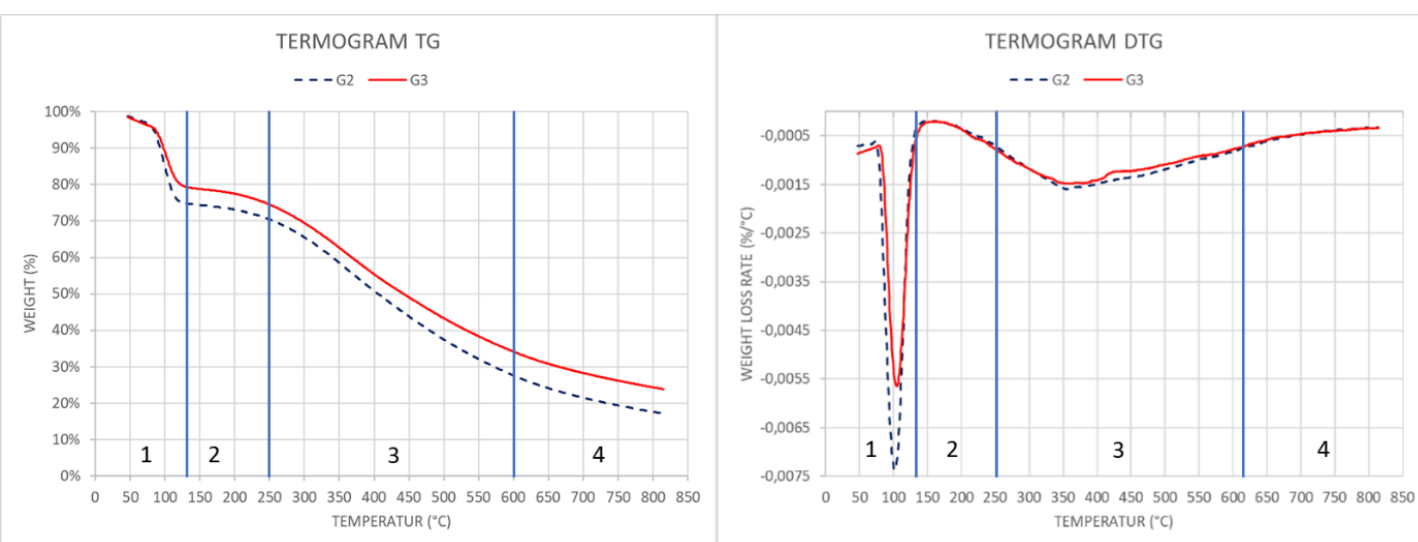

Gambar 3. Termogram TG dan DTG.

Tahap $1\left(40-130^{\circ} \mathrm{C}\right)$ terlihat penurunan massa kedua sampel cukup signifikan yang terlihat pada termogram TG dan berjalan dengan cepat seperti terlihat pada termogram DTG. Penurunan massa pada tahap ini berkaitan dengan proses dehidrasi yang terjadi selama pemanasan awal. Sampel G2 menunjukkan penurunan massa yang lebih signifikan dibandingkan dengan sampel G3. Hal ini disebabkan oleh kandungan air pada sampel G2 yang lebih tinggi dibandingkan sampel G3 (Tabel 1).

Tahap $2\left(130-250^{\circ} \mathrm{C}\right)$ sampel mengalami penurunan massa yang relatif kecil dengan laju penurunan massa yang lambat. Tahap ini bersesuaian dengan proses pirolisis lambat, pada saat gas-gas $\mathrm{CO}_{2}$ dan $\mathrm{CH}_{4}$ yang teradsorpsi pada permukaan pori-pori batubara terlepas (Song dkk., 2017). Selain itu pada tahap ini juga terjadi proses evolusi gugus-gugus fungsi yang bersifat labil seperti karboksil membentuk $\mathrm{CO}_{2}$ dan $\mathrm{CH}_{4}$. Kedua sampel memberikan termogram DTG yang hampir mirip pada tahap ini (Gambar 3).

Tahap $3\left(250-600^{\circ} \mathrm{C}\right)$ merupakan tahap pirolisis cepat, pada saat terjadinya primary cracking pada rantai karbon senyawa-senyawa batubara (Taylor dkk., 1998; Song dkk., 2017). Pada tahap ini zat terbang seperti $\mathrm{CO}_{2}, \mathrm{CH}_{4}$, dan gas-gas organik dan anorganik yang lain akan terbentuk dalam jumlah yang besar sehingga sering juga disebut sebagai tahap devolatilisasi. Termogram dari kedua sampel menunjukkan perbedaan, dimana sampel G2 lebih banyak mengalami penurunan massa (TG) dan lebih cepat laju penurunan massanya (DTG). Hal ini berkaitan dengan kandungan zat terbang pada sampel G2 yang lebih besar dibandingkan dengan sampel G3 (Tabel 1). Tahap $4\left(600-815^{\circ} \mathrm{C}\right)$ merupakan tahap secondary cracking, yaitu pada saat terjadinya pemutusan rantai karbon dari hidrokarbon rantai panjang yang telah terbentuk pada tahap sebelumnya (Taylor dkk., 1998; Song dkk., 2017). Penurunan massa pada tahap ini relatif lebih kecil dan laju penurunan massanya juga relatif lebih lambat. Kedua sampel menunjukkan termogram yang hampir mirip pada tahap ini.

Dari pembahasan perilaku termal di atas dapat diketahui bahwa sampel G2 mengalami penurunan massa dan juga mempunyai laju penurunan massa yang lebih tinggi dibandingkan sampel G3. Penurunan massa selama proses pirolisis dengan TGA pada temperatur tinggi $\left(>130^{\circ} \mathrm{C}\right)$ berkaitan dengan reaktivitas bahan organik selama pemanasan. Analisis dilakukan dengan medium gas nitrogen yang bersifat inert. Dengan demikian reaktivitas yang dimaksud di sini bukan merupakan reaktivitas terhadap reaktan yang ditambahkan, namun merupakan reaktivitas sehubungan dengan pemutusan ikatan kimia karena pemanasan. Selain itu juga reaktivitas ini berkaitan dengan kecenderungan unsur-unsur yang terlepas dari senyawa batubara untuk bereaksi satu dengan yang lain. Berdasarkan hal ini maka dapat diinterpretasikan bahwa senyawa-senyawa organik pada sampel G2 lebih reaktif daripada sampel G3.

Maseral merupakan unit terkecil bahan organik yang secara fisik dapat dilihat di bawah mikroskop. Masing-masing maseral mempunyai karakteristik fisik dan kimia yang berbeda-beda. Secara kimia maseral huminit didominasi oleh unsur oksigen. Maseral liptinit tersusun dari senyawa hidrokarbon rantai panjang sehingga mengandung lebih banyak hidrogen. Maseral inertinit merupakan bahan organik hasil oksidasi dan lebih banyak mengandung unsur karbon yang berikatan dengan sesama karbon sehingga cenderung bersifat inert atau tidak reaktif (Taylor dkk., 1998; Flores, 2014).

Memperhatikan uraian tentang karakteristik maseral di atas, perbedaan reaktivitas bahan organik pada sampel G2 dan G3 yang diindikasikan dari analisis termogravimetri kemungkinan besar dipengaruhi oleh perbedaan komposisi maseralnya. Sampel G3 mengandung maseral inertinit yang jauh lebih besar $(18,4 \% \mathrm{v} / \mathrm{v})$. Maseral inertinit yang cenderung inert atau tidak reaktif menyebabkan penurunan massa 
dan laju penurunan massanya menjadi kecil. Berbeda dengan sampel G2 yang lebih sedikit mengandung maseral inertinit $(6,4 \% \mathrm{v} / \mathrm{v})$, maseral lain (huminit dan liptinit) akan lebih banyak yang bereaksi selama proses thermal cracking menghasilkan zat terbang $\left(\mathrm{CO}_{2}, \mathrm{CH}_{4}\right.$, dII.) yang lebih banyak. Untuk memperkuat interpretasi ini, dibuat grafik yang menghubungkan kandungan maseral inertinit terhadap kandungan zat terbang (Gambar 4). Kedua prameter tersebut berbanding terbalik yang mengindikasikan bahwa komposisi maseral inertinit mempengaruhi reaktivitas batubara selama pirolisis.

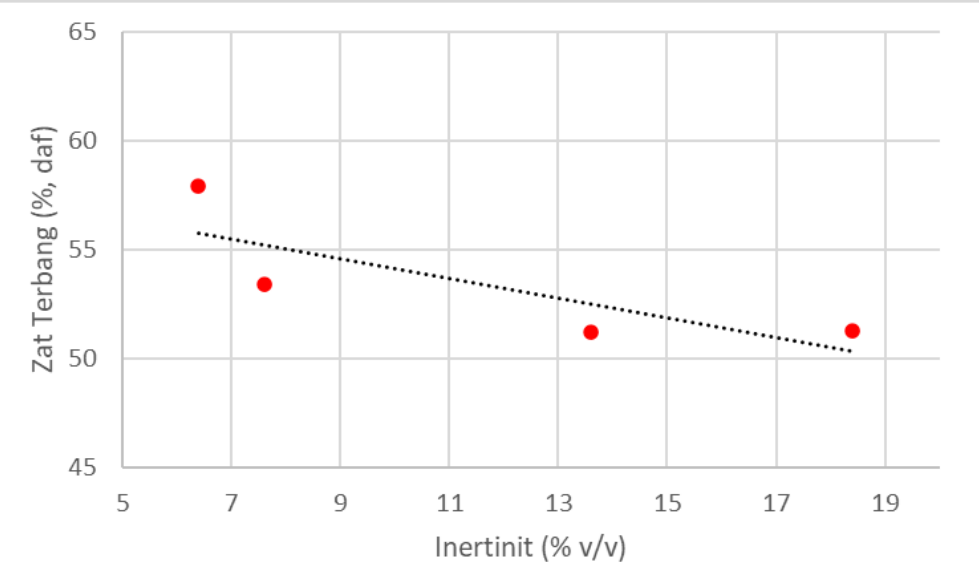

Gambar 4. Hubungan antara kandungan inertinit dengan kandungan zat terbang dan karbon tertambat.

Jenis pemanfaatan batubara secara nonkonvensional umumnya ditentukan oleh reaktivitas bahan organiknya. Gasifikasi merupakan sebuah proses konversi batubara menjadi gas dengan mereaksikannya dengan reaktan berupa gas oksigen-terbatas atau $\mathrm{CO}_{2}$. Batubara yang mempunyai kandungan inertinit lebih banyak akan mempunyai reaktivitas gasifikasi yang lebih rendah sehingga kurang optimal untuk dimanfaatkan dengan gasifikasi (Collot, 2006; Ozer dkk., 2017). Demikian pula dengan pencairan batubara yang proses utamanya adalah hidrogenasi. Proses hidrogenasi memerlukan bahan organik yang reaktif, sehingga apabila sebuah batubara mempunyai kandungan maseral inertinit yang cukup tinggi akan kurang sesuai untuk dimanfaatkan dengan teknologi pencairan (Chen dan Ma, 2002).

\section{KESIMPULAN}

Sampel batubara Muara Wahau yang diteliti mempunyai komposisi maseral yang bervariasi. Kandungan maseral inertinit mempengaruhi reaktivitas batubara yang diinterpetasikan dari analisis TGA. Semakin tinggi kandungan inertinit, maka batubara cenderung kurang reaktif selama pemanasan. Hal ini memberikan implikasi bahwa batubara yang didominasi oleh maseral inertinit kurang sesuai untuk dimanfaatkan dengan metode yang dipengaruhi oleh reaktivitas bahan organiknya seperti gasifikasi atau pencairan.

\section{UCAPAN TERIMA KASIH}

Penulis mengucapkan terima kasih kepada National Coal Institut, Oviedo, Spanyol yang telah memberikan kesempatan kepada penulis pertama untuk melakukan analisis TGA pada tahun 2011. Ucapan terima kasih juga disampaikan kepada semua pihak yang telah memberikan kontribusi terhadap penelitian dan penulisan paper ini.

\section{DAFTAR PUSTAKA}

Bryers, R.W. (1995) Investigation of the reactivity of macerals using thermal analysis. Fuel Processing Technology 44, 25-54.

Chen, P., Ma, J. (2002) Petrographic characteristics of Chinese coals and their application in coal utilization processes. Fuel 81, 1389-1395.

Collot, A. (2006) Matching gasification technologies to coal properties. International Journal of Coal Geology $75,191-212$.

Ditjen Minerba (2020) Laporan Kinerja Tahun 2019. Direktorat Jenderal Mineral dan Batubara, Kementerian Energi dan Sumberdaya Mineral, Jakarta: $168 p$.

Flores, R.M. (2014) Coal and Coalbed Gas, Fueling the Future. Elsevier, Amsterdam: 697p.

Ozer, M., Basha, O.M., Stiegel, G., Morsi, B. (2017) Effect of coal nature on the gasification process. In: Wang and Stiegel (Eds), Integrated Gasification Combined Cycle (IGCC) Technologies, Elsevier, Amsterdam.

Song, H., Liu, G., Zhang, J., Wu, J. (2017) Pyrolysis characteristics and kinetics of low rank coals by TG-FTIR method. Fuel Processing Technology 156, 454-460. 
Indonesian Mining Professionals Journal Volume 2, Nomor 2, November 2020 : 57 - 64

Stach, E., Mackowsky, M.T., Teichmiiller, M., Taylor, G.H., Chandra, D., Teichmilller, R. (1982) Stach's Textbook of Coat Petrology 3rd ed. Gebruder Borntraeger, Berlin: 535p

Supriatna, S., Abidin, Z.A. (1995) Peta Geologi Lembar Muara Wahau. P3G, Bandung.
Taylor, G.H., Teichmuller, M., Davis, A., Diessel, C.F.K. Littke, R., Robert, P. (1998) Organic Petrology. Gebruder Borntraeger, Berlin: 704p.

Zhao, Y., Hu, H., Jin, L., Bo, W. (2011) Pyrolysis behavior of vitrinite and inertinite from Chinese Pingshuo coal by TG-MS and in a fixed bed reactor. Fuel Processing Technology 92, 780-786. 
Indonesian Mining Professionals Journal Volume 2, Nomor 2, November 2020 : 57 - 64 